\title{
Lại vẫn chuyện dài khó dừng về JIF
}

\author{
Nguyễn Minh Hoàng
}

Ritsumeikan APU

Oct. 23, 2021

Năm 2015, Tổng biên tập I. M. Verma của Kỷ yếu Viện hàn lâm Khoa học Hoa Kỳ (PNAS) có bài viết rất hay về hệ số tác động JIF, viết tắt của Journal Impact Factor (hoặc IF, Impact Factor) đây uy quyền của ISI Thomson Reuters, mà về sau đã bán cho Clarivate Analytics, và nằm trong hệ thống ngày nay gọi là Web of Science Group. Bài viết tạo ấn tượng đáng đọc ngay từ cái tiêu đề "Impact, not impact factor" [1].

Câu cuối cùng của bài chính là thể hiện quan điểm rõ ràng của $P N A S$ rằng, ảnh hưởng chân chính của khoa học là thứ những người làm nghiên cứu theo đuổi miệt mài, chứ không phải con số ước lệ gọi là hệ số tác động JIF. Ông viết:

"At PNAS, which is celebrating its 100th anniversary, the focus has always been on impact, not impact factors."

Tưởng như, cái kết này là quá đủ cho câu chuyện dài tập về những tranh cãi, phàn nàn, tuyên bố chung về tiết chế hành vi sử dụng JIF sao cho phù hợp với bản chất của con số. Nhưng hóa ra không phải. Kể từ khi Verma viết bài đó, vào lúc PNAS tưng bừng kỷ niệm sinh nhật 100 năm của ấn phẩm, thì tiền của vẫn tiếp tục đổ vào các ấn phẩm có hệ số tác động cao. Nói cho chính xác thì một phần rất đáng kể công sức, và theo đó là chi phí liên quan cho việc sản xuất và theo đuổi xuất bản, đã, đang và vẫn sẽ tiếp tục theo đuổi những con số lớn JIF. Khi chi phí đó càng lớn thì sẽ càng khiến các xã hội đặt câu hỏi nghi hoặc về hiệu quả đầu tư khoa học, vì JIF không đồng nghĩa với tác động tích cực lên sự đổi thay của nhân sinh và thể trạng xã hội [2].

Thực tế các kết quả nghiên cứu nghiêm chỉnh từ dữ liệu học thuật cho thấy việc tồn tại các khiếm khuyết và cả những sai lầm nghiêm trọng, tới mức cần phải đính chính hoặc thậm chí rút một phần, toàn phần, của công bố ở những tạp chí rất uy tín như New England Journal of Medicine hay Lancet—cũng đồng nghĩa với mức JIF rất caongày càng trở nên phổ biến [3]. Thế nhưng, dường như điều đó chẳng liên quan gì tới ảnh hưởng bao trùm, dai dẳng và ngày càng sâu đậm hơn của JIF trong cộng đồng khoa học toàn cầu. 
Vậy nên, đễn 2019, lại vẫn PNAS, Tổng biên tập kế nhiệm M. R. Berenbaum lại vẫn phải tiếp tục nói về tác động tiêu cực của JIF đối với khoa học, nhưng mượn khía cạnh đang được xã hội quan tâm, đó là với nhóm yếu thế hơn, những người mới vào nghề ECR (early-career researchers).

Berenbaum có đoạn viết như sau:

"PNAS editors also have refrained from writing celebratory editorials about any upward movement of our JIF. We have signed on to the San Francisco Declaration on Research Assess ment (DORA), issued in 2013 to encourage reforms in evaluations of scientific quality by publishers, funding agencies, institutions, organizations that create and provide metrics, and individual scientists".

Cô ấy không nói sai. Berenbaum cũng rất thẳng thắn, và lịch sự, chỉ trích sự lạm dụng JIF một nguồn cơn gây ra nhiều khó khăn và cả hiểu nhầm về sứ mệnh của công việc khoa học.

Dường như để cho thấy cách hiểu này không phải chỉ của $P N A S$, mà có cả sự đồng thuận của nhiều người đồng nghiệp có uy tín, bài đã nhắc đến $B$. Alberts của Science, với bài viết chỉ trích cũng không kém trực diện "Impact factor distortions" [5], hay Schekman, Watt \& Weigel [6], hoặc xã luận Nature [7].

Câu chuyện khúc mắc dai dẳng với JIF có nguồn cơn từ một thực tế là bản thân JIF có giá trị sử dụng, thuận tiện, và sẵn sàng (cả về dữ liệu và biểu mẫu báo cáo). Hơn nữa, xã hội và một bộ phận lớn của giới khoa học có nhu cầu truyên thông dựa trên một số dấu hiệu thống kê đủ đơn giản, dễ hình dung và được chấp nhận rộng rãi. Và JIF rõ ràng là đáp ứng được nhu cầu đó.

Cuối cùng, cũng phải nói tới một thực tế khó chối cãi rằng các ấn phẩm uy tín mà giới nghiên cứu muốn đăng thì cũng thường có JIF rất cao. Một ví dụ cụ thể là JIF năm 2020 của Science là 47.728, Lancet 79.321, eLife 8.14, Nature 49.962, và PNAS 11.205, theo Journal Citation Reports 2021 [8].

Như thế, câu chuyện dài về JIF sẽ khó lòng mà dừng lại được. Và bây giờ, ngoài JIF người ta cũng đang tiếp tục dùng cả CiteScore của Scopus, cũng như động viên nhau sử dụng "số đo ảnh hưởng thay thế" như Altmetric (của Digital Science, cũng là hãng sở hữu thương hiệu Dimensions) hay PlumX (của Elsevier)!

Mà dường như có một luật bất thành văn như sau. Với những thứ đã thành lịch sử, có chỗ trên bệ tượng đài nhiều thập kỷ nay, và trở thành bắt buộc như JIF, thì càng 
nhiều thứ mới ra đời nhằm cố gắng thay thế, càng nhiều dư luận về nỗ lực hạ bệ, thì nó lại càng nổi bật và trang trọng hơn. Nói giàu hình tượng như Bà Huyện Thanh Quan thì là: "Đá vẫn trơ gan cùng tuế nguyệt".

Cho nên, trong cái tâm thế của việc tiên phong, chủ động với công việc xuất bản học thuật trong thời đại đang nhiều đổi thay [9], thì cũng không thể né tránh việc hiểu kỹ về các số đo được sử dụng rộng rãi, về sự tranh cãi sôi nổi với nhiều quan điểm khác biệt cũng như những gì đã công nhận hầu khắp. Trong những thứ cần phải chủ động tìm hiểu nội dung, giá trị, xu hướng mới, có cái gọi là hệ số tác động JIF cùng với câu chuyện dài khó dừng.

\section{References}

[1] Verma, I. M. (2015). Impact, not impact factor. Proceedings of the National Academy of Sciences of the United States of America, 112(26), 7875-7876.

[2] Vuong, Q. H. (2018). The (ir) rational consideration of the cost of science in transition economies. Nature Human Behaviour, 2(1), 5-5.

[3] Vuong, Q. H. (2020). Reform retractions to make them more transparent. Nature, 582(7811), 149-149.

[4] Berenbaum, M. R. (2019). Impact factor impacts on early-career scientist careers. Proceedings of the National Academy of Sciences of the United States of America, 116(34), 16659-16662.

[5] Alberts, B. (2013). Impact factor distortions. Science, 340(6134), 787-787.

[6] Schekman, R., Watt, F. M., \& Weigel, D. (2013). eLife and early career researchers. elife, 2, e01633.

[7] Editorial. (2005). Not-so-deep impact. Nature, 435(7045), 1003-1004.

[8] Clarivate Analytics. (2021). Journal Citation Reports 2021. Web of Science: https://clarivate.com/webofsciencegroup/solutions/journal-citation-reports/

[9] Vuong, Q. H. (2019). Breaking barriers in publishing demands a proactive attitude. Nature Human Behaviour, 3(10), 1034-1034. 